\title{
Usulan Penyelesaian Masalah Rekayasa Tanah untuk Jalan dan Gedung di Atas Tanah Ekspansif Studi Kasus Surabaya Barat
}

\author{
Samuel Giovanni, Indrasurya B. Mochtar, dan Noor Endah Mochtar \\ Departemen Teknik Sipil, Fakultas Teknik Sipil, Lingkungan dan Kebumian, Institut Teknologi Sepuluh Nopember \\ (ITS) \\ e-mail: indrasurya@ce.its.ac.id
}

\begin{abstract}
Abstrak-Tanah ekspansif merupakan salah satu jenis tanah bermasalah yang paling sering ditemui di Indonesia. Tingginya kemampuan kembang susut saat mengalami perubahan kadar air merupakan sifat yang menonjol pada tanah ekspansif. Dalam kondisi basah, volume tanah ekspansif akan bertambah dan sebaliknya di saat kering, volume tanah ekspansif akan mengecil. Perubahan volume inilah yang sering menyebabkan kerusakan pada bangunan sipil yang berdiri di atas tanah ekspansif. Surabaya Barat juga mengalami masalah akibat tanah ekspansif, oleh karena itulah dibutuhkan suatu alternative usulan penyelesaian untuk menyelesaikan masalah ini. Kontur tanah Surabaya Barat yang naik turun menyerupai bukit dan lembah membuat perencanaan perbaikan tanah untuk jalan dan gedung di 2 jenis lokasi tersebut menjadi berbeda. Hal ini disebabkan karena, daerah lembah akan sangat mungkin tergenang air pada saat musim penghujan dikarenakan air hujan secara langsung maupun air hujan yang mengalir dari bukit, oleh karena itu digunakan metode Keep it Wet untuk setiap perencanaan yang dilakukan. Sedangkan di daerah bukit tidaklah demikian, pembasahan hanya terjadi di daerah permukaan karena sifat alami air yang mengalir ke tempat yang lebih rendah menyebabkan tidak mungkinnnya terjadi genangan. Namun tetap dibutuhkan perencanaan untuk memastikan agar tidak mempengaruhi kadar air dalam tanah di atas bukit. Oleh karena itu pada perencanaan di Bukit, digunakan metode Keep it Dry. Dalam Studi ini penulis telah membandingkan 2 alternatif untuk tiap kondisi. Didapatkan melalui Studi ini bahwa alternatif terbaik berdasarkan biaya untuk Perencanaan Perbaikan Tanah untuk Jalan di Bukit adalah Penggunaan Geomembran pada Parit; Jalan di Lembah adalah Penggunaan Geomembran di Bawah Badan Jalan; Rumah di Bukit dan Lembah adalah Penggunaan Geomembran di sekeliling rumah.
\end{abstract}

Kata Kunci-Tanah Ekspansif, Rekayasa Tanah Ekspansif, Keep it Wet, Keep it Dry, S urabaya Barat.

\section{PENDAHULUAN}

A. Latar Belakang

DEningKatan pembangunan infrastruktur di Indonesia, Perutama di daerah perkotaan mengakibatkan sulitnya mencari lahan yang memadai. Pembangunan jalan dan perumahan sedang banyak dilakukan baik oleh pemerintah maupun developer. Tentunya daerah dengan tanah yang baik merupakan sasaran utama lokasi pembangunan. Namun seiring dengan berjalannya waktu, lahan dengan tanah yang baik semakin sedikit sehingga perencanaan konstruksi bangunan sipil di kondisi tanah yang buruk tidaklah jarang dijumpai di Indonesia. Salah satu contoh kondisi tanah yang buruk adalah tanah ekspansif.

Tanah ekspansif merupakan salah satu jenis tanah bermasalah yang paling sering ditemui di Indonesia. Tingginya kemampuan kembang susut saat mengalami perubahan kadar air merupakan sifat yang menonjol pada tanah ekspansif. Dalam kondisi basah, volume tanah ekspansif akan bertambah/mengembang dan sebaliknya di saat kering, volume tanah ekspansif akan mengecil/menyusut. Perubahan volume inilah yang sering menyebabkan kerusakan pada bangunan sipil yang berdiri di atas tanah ekspansif.

Surabaya Barat sebagai salah satu pusat utama dari pembangunan di Surabaya tidak lepas dari masalah tanah ekspansif dimana banyak ditemui jalan-jalan yang bergelombang dan lantai rumah yang rusak, terutama di saat pergantian musim. Kondisi ini tentu saja sangat mengkhwatirkan mengingat Surabaya Barat akan menjadi pusat pembangunan di Surabaya. Oleh karena itulah dibutuhkan suatu alternatif usulan penyelesaian untuk menyelesaikan masalah tanah ekspansif yang dipergunakan untuk jalan dan gedung di Surabaya Barat.

Kontur tanah yang naik turun menyerupai bukit dan lembah sering dijumpai di daerah perumahan Citraland. Hal ini tentu saja membuat perencanaan perbaikan tanah untuk konstruksi jalan dan gedung di daerah bukit dan lembah akan menjadi berbeda. Daerah lembah akan lebih mudah tergenang air di saat musim hujan, yang bukan hanya disebabkan oleh air hujan yang turun namun juga muka air tanah yang naik. Daerah bukit tidak terlalu dipengaruhi oleh muka air tanah karena elevasinya yang lebih tinggi, namun harus melakukan perencanaan parit dan perlindungan talud. Parit dibutuhkan agar pada saat hujan datang, air yang jatuh ke permukaan tanah langsung segera dialirkan ke bawah sedangkan perlindungan talud dilakukan dengan tujuan agar pada saat musim hujan tidak terjadi kelongsoran pada daerah lereng. 


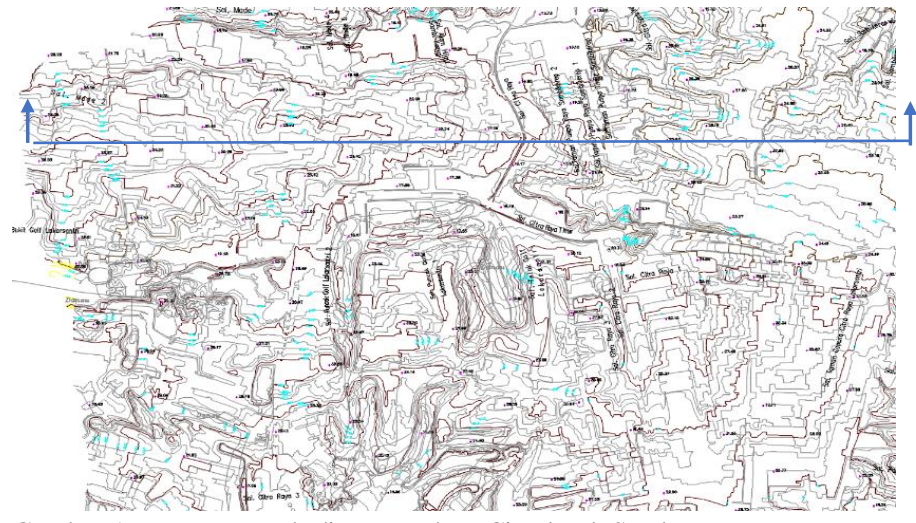

Gambar 1 Kontur Tanah di Perumahan Citraland, Surabaya Barat

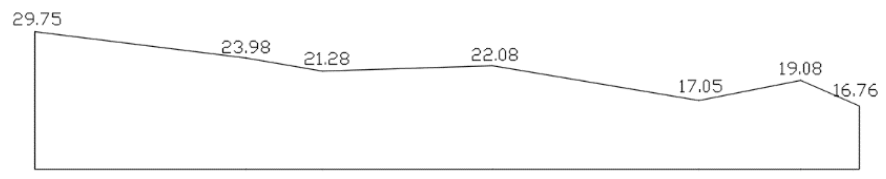

Gambar 2 Sketsa Potongan Melintang Kontur

Studi ini akan membahas tentang alternatif perbaikan/rekayasa tanah ekspansif untuk jalan dan pondasi dangkal di Surabaya Barat. Hasil dari perencanaan studi ini akan dapat dijadikan referensi untuk perbaikan tanah dan jenis pondasi dalam pembangunan jalan dan rumah di Surabaya Barat.

\section{B. Rumusan Masalah}

1. Apa klasifikasi tanah di wilayah studi menurut USCS dan AASHTO?

2. Berapakah harga aktivitas tanah (A) yang menyebabkan sifat kembang susut?

3. Apa usulan penyelesaian perbaikan/rekayasa tanah kembang susut untuk konstruksi jalan yang berada di daerah lembah dan bukit?

4. Bagaimana sistem perbaikan/pengamanan talud atau lereng dari tanah yang kembang susut?

5. Apa usulan perbaikan/rekayasa tanah kembang susut untuk konstruksi rumah (pondasi) di daerah bukit dan lembah?

6. Apa usulan perbaikan/rekayasa tanah untuk jalan dan rumah di Surabaya Barat yang paling efisien untuk di daerah bukit dan lembah?

\section{Batasan Masalah}

Batasan masalah pada Studi ini adalah:

1. Tidak membahas perhitungan bangunan jalan

2. Tidak membahas perhitungan bangunan gedung

3. Data-data yang digunakan diambil dari Surabaya Barat khususnya Kompleks Citraland

4. Sebagian besar data tanah merupakan data sekunder.

5. Daerah Lembah diasumsikan tergenang air saat musim hujan.

6. Tidak Merencanakan Sistem Drainase Perumahan.

\section{METODOLOGI}

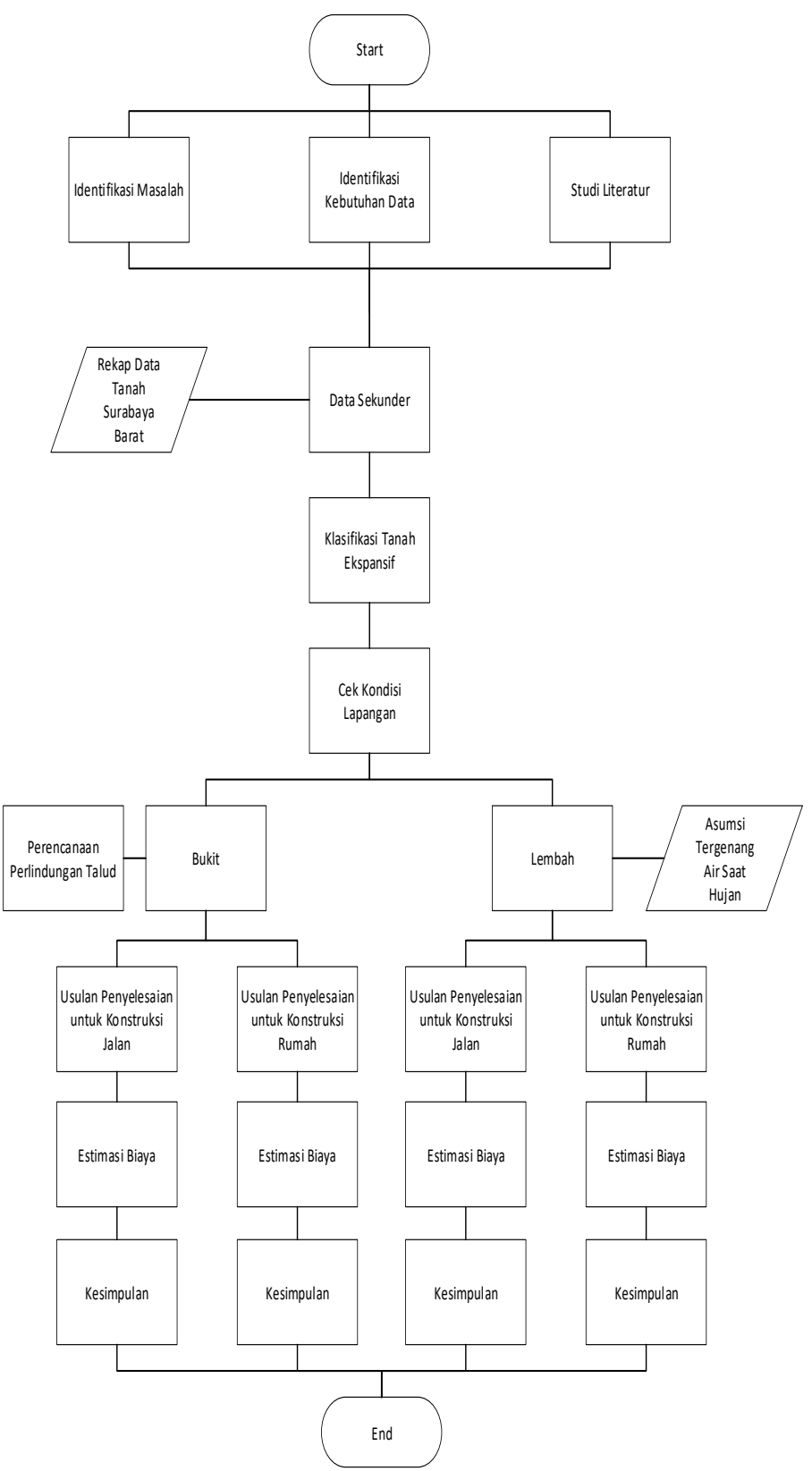

\section{HASIL DAN PEMBAHASAN}

\section{A. Analisa Data Tanah}

Data tanah yang digunakan pada perencanaan ini ada 2 yaitu BH-1 dan BH-2. Kedua data tersebut memiliki nilai parameter yang relatif sama maka pada perencanaan ini kedua data tersebut akan dirata-rata yang kemudian akan ditabulasikan pada Tabel 1 Data tersebut kemudian akan diklasifikasikan menggunakan peraturan USCS dan AASHTO. Hasil klasifikasi dapat lebih jelas dilihat pada Tabel 1. 
Tabel 1.

Nilai Rata-rata Parameter Data Tanah

\begin{tabular}{|c|c|c|c|c|c|c|c|}
\hline \multirow{2}{*}{$\begin{array}{c}\text { Jenis Pengujian } \\
\text { Parameter }\end{array}$} & \multirow{2}{*}{ Satuan } & \multicolumn{6}{|c|}{ Kedalaman } \\
\hline & & $0-8,0 \mathrm{~m}$ & $8,0-13,0 m$ & $13,0-18,0 \mathrm{~m}$ & $18,0-25,5 \mathrm{~m}$ & $25,5-45,5 \mathrm{~m}$ & $45,5 m-60,5 m$ \\
\hline \multicolumn{8}{|l|}{ Indeks Properti } \\
\hline Kadar Air (wc) & $\%$ & 41.575 & 40.17 & 40.9 & 39.695 & 38.42 & 36.28 \\
\hline Gs & & 2.598 & 2.6505 & 2.6625 & 2.6025 & 2.688 & 2.712 \\
\hline Berat Vol. Basah ( $($ sat) & $\mathrm{KN} / \mathrm{m}^{3}$ & 16.78 & 17.155 & 17.305 & 17.32 & 17.68 & 18.06 \\
\hline Berat Vol. Kering $(\gamma d)$ & $\mathrm{KN} / \mathrm{m}^{3}$ & 11.015 & 11.485 & 11.7 & 11.88 & 12.23 & 12.77 \\
\hline \multicolumn{8}{|c|}{ Uji Geser Langsung (Direct Shear Test) } \\
\hline Kohesi (Cu) & $\mathrm{KN} / \mathrm{m}^{2}$ & 25 & 50.5 & 82.5 & 90 & 91 & 153 \\
\hline \multicolumn{8}{|l|}{ Grain Size } \\
\hline Lolos Ayakan no. 200 & $\%$ & 91.555 & 92.47 & 91.45 & 92.43 & 92.11 & 91.21 \\
\hline Komposisi Lempung & $\%$ & 74.665 & 73.225 & 75.505 & 75.38 & 72.94 & 75.3 \\
\hline \multicolumn{8}{|l|}{ Atterberg Limit } \\
\hline Batas Cair (LL) & $\%$ & 64.56 & 64.685 & 65.385 & 65.35 & 64.53 & 63.54 \\
\hline Batas Plastis (PL) & $\%$ & 32.145 & 30.75 & 32.13 & 31.43 & 33.15 & 33.47 \\
\hline Indeks Plastisitas (PI) & $\%$ & 32.415 & 33.935 & 33.255 & 33.92 & 31.38 & 30.07 \\
\hline \multicolumn{2}{|c|}{ Klasifikasi Tanah Menurut USCS } & $\mathrm{CH}$ & $\mathrm{CH}$ & $\mathrm{CH}$ & $\mathrm{CH}$ & $\mathrm{CH}$ & $\mathrm{CH}$ \\
\hline \multicolumn{2}{|c|}{ Klasifikasi Tanah Menurut AASHTO } & A-7-5 & $A-7-5$ & A-7-5 & A-7-5 & A-7-5 & A-7-5 \\
\hline
\end{tabular}

Tabel 2

Peraturan USCS

\begin{tabular}{|c|c|c|c|c|c|c|c|}
\hline \multirow{8}{*}{ 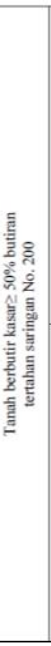 } & \multirow{4}{*}{ 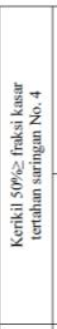 } & \multirow{2}{*}{ 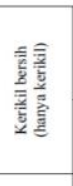 } & \multirow[t]{2}{*}{ ow } & \multirow{2}{*}{ 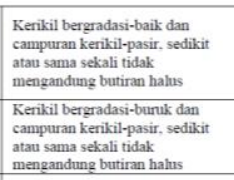 } & \multirow{8}{*}{ 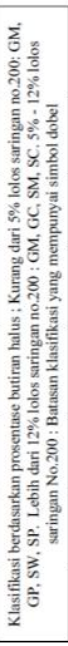 } & \multirow{2}{*}{\multicolumn{2}{|c|}{ 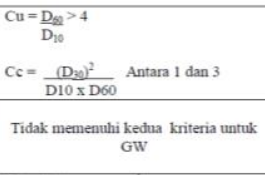 }} \\
\hline & & & & & & & \\
\hline & & \multirow{2}{*}{ 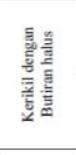 } & GM & $\begin{array}{l}\text { Kerikil berlanalu, campuran } \\
\text { kerikil-pasir-lanau }\end{array}$ & & $\begin{array}{l}\text { Batas-batas } \\
\text { Atterberg di } \\
\text { baxah ganis } \mathrm{A} \\
\text { atau } \mathrm{Pl}<4 \\
\end{array}$ & 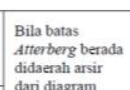 \\
\hline & & & $\omega C$ & $\begin{array}{l}\text { Kerikil berlempung, campuran } \\
\text { kerikil-pasir-lempung }\end{array}$ & & $\begin{array}{l}\text { Batas-batas } \\
\text { Atterberg di } \\
\text { baval ganis A } \\
\text { atau P P>7 }\end{array}$ & $\begin{array}{l}\text { dandasarisanum } \\
\text { pakaka } \\
\text { dipakai dobela } \\
\text { simbol }\end{array}$ \\
\hline & \multirow{4}{*}{ 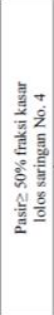 } & \multirow{2}{*}{ 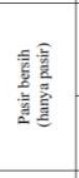 } & sw & 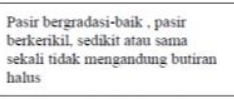 & & \multicolumn{2}{|c|}{ 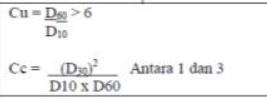 } \\
\hline & & & SP & $\begin{array}{l}\text { Pasir bereradasi-buruk, pasir } \\
\text { berkerikil, sedikit atau samaa } \\
\text { sekali tidask mengandung butiran } \\
\text { halus }\end{array}$ & & \multicolumn{2}{|c|}{$\begin{array}{l}\text { Tidak memenubik kedua kriteria unulk } \\
\text { SW }\end{array}$} \\
\hline & & \multirow{2}{*}{ 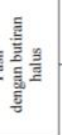 } & SM & $\begin{array}{l}\text { Pasir belinaul, campuran pasir- } \\
\text { lanaut }\end{array}$ & & $\begin{array}{l}\text { Batas-batas } \\
\text { Atterberg di } \\
\text { bawah ganis } \mathrm{A} \\
\text { atau } \mathrm{PI}<4 \\
\end{array}$ & \multirow{2}{*}{$\begin{array}{l}\text { Bila batas } \\
\text { Atterberg berada } \\
\text { didaerah assir } \\
\text { dari diagan } \\
\text { plastistias maka } \\
\text { dipakai dobel } \\
\text { simbol }\end{array}$} \\
\hline & & & sc & $\begin{array}{l}\text { Pasir berlempung, campuran } \\
\text { pasir-lempung }\end{array}$ & & 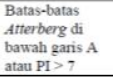 & \\
\hline \multirow{8}{*}{\multicolumn{2}{|c|}{ 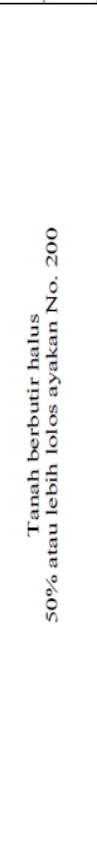 }} & \multirow{4}{*}{ 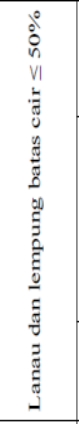 } & ML & $\begin{array}{l}\text { Lanaut anorganilik, pasir halus } \\
\text { sekali, serbul batuan, pasiri halus } \\
\text { berlanaulu atau berlempung }\end{array}$ & \multirow{2}{*}{\multicolumn{3}{|c|}{ 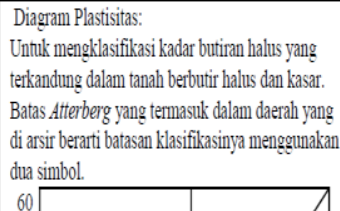 }} \\
\hline & & & & $\begin{array}{l}\text { Lempung anorganik dengan } \\
\text { plastisitas rendah sampai dengan }\end{array}$ & & & \\
\hline & & & CL & $\begin{array}{l}\text { sedang lempung berkerikil, } \\
\text { lempung berpasir, lempung } \\
\text { berlanaul, lempung "kurus" (lean } \\
\text { clays) }\end{array}$ & 60 & & \\
\hline & & & OL & $\begin{array}{l}\text { Lanaul-organik dan lempung } \\
\text { berlanau organilk dengan } \\
\text { plastisitas rendah }\end{array}$ & 30 & & \\
\hline & & 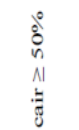 & $\mathrm{MH}$ & $\begin{array}{l}\text { Lanau anorganilk atau pasir halus } \\
\text { diatomae, atau lanau diatomae, } \\
\text { lanau yang elastis }\end{array}$ & & $711 \mathrm{ML}$ & ML atau OH \\
\hline & & $\frac{n}{\tilde{g}}$ & & Lempung anorganik dengan & 0 & $20 \quad 30$ & $\begin{array}{llll}50 & 60 & 70 & 80\end{array}$ \\
\hline & & 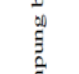 & $\mathrm{CH}$ & $\begin{array}{l}\text { plastisitas tinggi, lempung } \\
\text { "gemulu" (fat clays) }\end{array}$ & & Batas Cair $(9$ & \\
\hline & & 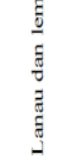 & $\mathrm{OH}$ & $\begin{array}{l}\text { Lempung organil dengan } \\
\text { plastisitas sedang sampai dengan } \\
\text { tinggi }\end{array}$ & Garis A & $\mathrm{PI}=0.73(\mathrm{LL}-20$ & \\
\hline $\begin{array}{l}\text { Tanah-t } \\
\text { kandung } \\
\text { tinggi }\end{array}$ & tanah & $\begin{array}{l}\text { dengan } \\
\text { sangat }\end{array}$ & PT & $\begin{array}{l}\text { Peat (gambut), muck, dan tanall- } \\
\text { tanah lain dengan kandungan } \\
\text { organik tinggi }\end{array}$ & & $\begin{array}{l}\text { untuk identifikas } \\
\text { hat di ASTM Des }\end{array}$ & $\begin{array}{l}\text { ecara visual dapat } \\
\text { nation D-2488 }\end{array}$ \\
\hline
\end{tabular}

Sumber: Hary Christady, 1996.
Tabel 3

Peraturan AASHTO

\begin{tabular}{|c|c|c|c|c|c|c|c|}
\hline \multirow{3}{*}{$\begin{array}{r}\text { Klasifikasi umum } \\
\text { Klasifikasi kelompok }\end{array}$} & \multicolumn{7}{|c|}{$\begin{array}{c}\text { Tanah berbutir } \\
\text { (35\% atau kurang dari seluruh contoh tanah lolos ayakan No. } 200\end{array}$} \\
\hline & \multicolumn{2}{|l|}{ A-1 } & \multirow{2}{*}{ A-3 } & \\
\hline & A-1-a & A-1-b & & A-2-4 & A-2-5 & A-2-2 & A-2-7 \\
\hline $\begin{array}{l}\text { Analisis ayakan (\% } \\
\text { lolos) } \\
\text { No. } 10 \\
\text { No. } 40 \\
\text { No. } 200\end{array}$ & $\begin{array}{l}\text { Maks } 50 \\
\text { Maks } 30 \\
\text { Maks } 15\end{array}$ & $\begin{array}{l}\text { Maks } 50 \\
\text { Maks } 25\end{array}$ & $\begin{array}{l}\text { Min } 51 \\
\text { Maks } 10\end{array}$ & Maks 35 & Maks 35 & Maks 35 & Maks 35 \\
\hline $\begin{array}{l}\text { Sifat fraksi yang lolos } \\
\text { ayakan No.40 } \\
\text { Batas Cair (LL) } \\
\text { Indeks Plastisitas (PI) }\end{array}$ & \multicolumn{2}{|l|}{ Maks 6} & NP & $\begin{array}{l}\text { Maks } 40 \\
\text { Maks } 10\end{array}$ & $\begin{array}{l}\text { Min } 41 \\
\text { Maks } 10\end{array}$ & $\begin{array}{l}\text { Maks } 40 \\
\text { Min } 11\end{array}$ & $\begin{array}{l}\text { Min } 41 \\
\text { Min } 41\end{array}$ \\
\hline $\begin{array}{l}\text { Tipe material yang } \\
\text { paling dominan }\end{array}$ & \multicolumn{2}{|c|}{$\begin{array}{l}\text { Batu pecah, kerikil } \\
\text { dan pasir }\end{array}$} & $\begin{array}{l}\text { Pasir } \\
\text { halus }\end{array}$ & \multicolumn{4}{|c|}{$\begin{array}{l}\text { Kerikil dan pasir yang berlanau atau } \\
\text { berlempung }\end{array}$} \\
\hline $\begin{array}{l}\text { Penilaian sebagai bahan } \\
\text { tanah dasar }\end{array}$ & \multicolumn{7}{|c|}{ Baik sekali sampai baik } \\
\hline Klasifikasi umum & \multicolumn{7}{|c|}{$\begin{array}{c}\text { Tanah berbutir } \\
\text { (Lebih dari 35\% dari seluruh contoh tanah lolos ayakan No.200 }\end{array}$} \\
\hline Klasifikasi kelompok & \multicolumn{2}{|l|}{ A-4 } & \multicolumn{2}{|l|}{ A-5 } & A- 6 & \multicolumn{2}{|l|}{ A-7 } \\
\hline $\begin{array}{l}\text { Analisis ayakan (\% } \\
\text { lolos) } \\
\text { No. } 10 \\
\text { No.40 } \\
\text { No. } 200 \\
\end{array}$ & \multicolumn{2}{|l|}{$\operatorname{Min} 36$} & \multicolumn{2}{|l|}{$\operatorname{Min} 36$} & $\operatorname{Min} 36$ & \multicolumn{2}{|c|}{$\operatorname{Min} 36$} \\
\hline $\begin{array}{l}\text { Sifat fraksi yang lolos } \\
\text { ayakan No.40 } \\
\text { Batas Cair (LL) } \\
\text { Indeks Plastisitas (PI) }\end{array}$ & \multicolumn{2}{|l|}{$\begin{array}{l}\text { Maks } 40 \\
\text { Maks } 10\end{array}$} & \multicolumn{2}{|l|}{$\begin{array}{l}\text { Maks } 41 \\
\text { Maks } 10\end{array}$} & Maks 40 & \multicolumn{2}{|c|}{$\begin{array}{l}\operatorname{Min} 41 \\
\operatorname{Min} 11\end{array}$} \\
\hline $\begin{array}{l}\text { Tipe material yang } \\
\text { paling dominan }\end{array}$ & \multicolumn{4}{|c|}{ Tanah berlanau } & \multicolumn{3}{|c|}{ Tanah Berlempung } \\
\hline $\begin{array}{l}\text { Penilaian sebagai bahan } \\
\text { tanah dasar }\end{array}$ & \multicolumn{7}{|c|}{ Biasa sampai jelek } \\
\hline
\end{tabular}

\section{B. Perilaku Tanah di Wilayah Studi}

Pada perhitungan ini digunakan metode perhitungan Skempton yang menggunakan data Indeks Plastisitas dan Besar Fraksi Lempung pada Tanah.
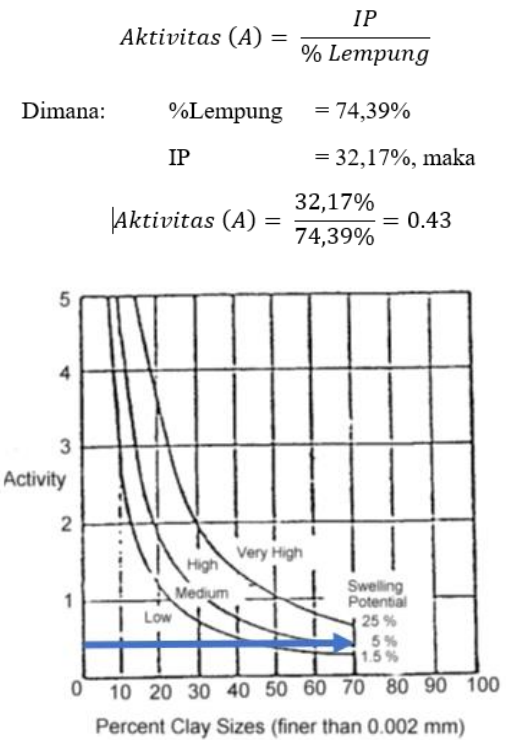

Gambar 3. Identifikasi Potensi Pengembangan Metode Skempton

Didapatkan bahwa tanah ekspansif di Citraland termasuk dalam kategori tanah yang memiliki potensi mengembang tinggi sehingga memerlukan usulan penyelesaian perbaikan tanah untuk tanah ekspansif di bawah konstruksi jalan dan rumah.

\section{Perencanaan Perlindungan Talud}

Pada studi ini akan direncanakan penggunaan geomembrane untuk melindungi talud. Talud yang perlu untuk dilindungi adalah talud yang berada di dekat dengan 
konstruksi dan talud yang tidak stabil $(\mathrm{SF}<1,5)$. Untuk mengetahui kestabilan talud digunakan program bantu seperti Xstable, Geosolope, dsbnya untuk melakukan analisa stabilitas.

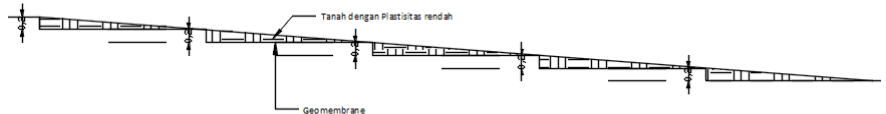

Apabila ditemukan di lapangan bahwa terdapat talud yang berada di dekat konstruksi jalan ataupun rumah dan memiliki kemiringan yang curam/SF $<1,5$ maka seperti terlihat pada Gambar 4.3, talud akan dibagi menjadi beberapa lapisan dengan ketebalan lapisan sebesar $20 \mathrm{~cm}$. Kemudian padatkan tanah talud di tiap lapisan tersebut kemudian tutup dengan geomembrane, lalu tutup geomembrane dengan sirtu kemudian ditutup lagi dengan tanah yang memiliki plastisitas rendah.

\section{Usulan Penyelesaian}

Pada prinsipnya, untuk menyelesaikan permasalahan tanah ekspansif adalah dengan cara menjaga agar kadar air di dalam tanah dalam kondisi yang konstan. Ada banyak alternatif yang dapat dilakukan untuk menyelesaikan permasalahan tanah ekspansif seperti dapat dilihat pada Sub Bab 2.8. Namun pada Studi ini tidak semua perencanaan dapat dilakukan secara efektif di semua tempat. Hal ini disebabkan kontur tanah Citraland naik turun menyerupai bukit dan lembah sehingga menyebabkan perencanaan perbaikan tanah ekspansif untuk jalan dan rumah di kedua tempat ini menjadi berbeda.

\section{Usulan Penyelesaian di Bukit}

Bukit pada Studi ini dimaksudkan dengan daerah yang memiliki elevasi lebih tinggi daripada daerah di sekitarnya dan nyaris tidak mungkin terjadi genangan air. Hal ini dikarenakan air hujan yang jatuh dari atas langsung mengalir ke daerah yang lebih rendah sesuai dengan sifat alami dari air. Kondisi ini menyebabkan pembasahan akibat air hujan hanya terjadi di permukaan saja, tidak sampai masuk ke dalam tanah. Melihat bahwa air hanya membasahi permukaan saja, maka pada perencanaan di bukit akan dilakukan perencanaan agar kondisi tanah dasarnya dalam kondisi kering sepanjang musim, yang bisa disebut dengan metode Keep It Dry. Metode ini dilakukan pada saat musim kemarau, dimana akibat panas sinar matahari maka air di dalam tanah akan menguap dan menyebabkan kondisi kadar air tanah berada dalam kondisi minimum. Beberapa alternatif yang dapat digunakan dengan metode ini adalah sebagai berikut:

1. Manajemen Air

2. Penggunaan Lapisan Kedap Air (Geomembran)

3. Penggantian Tanah Dasar

4. Stabilisasi Kapur untuk Jalan

Pada perencanaan ini, untuk konstruksi jalan akan direncanakan dan dibandingkan antara Penggunaan Geomembran pada Parit serta Stabilisasi Kapur. Sedangkan untuk konstruksi rumah akan drencanakan dan dibandingkan antara Penggantian Tanah Dasar dan Penggunaan Geomembran di sekeliling rumah.

a. Perencanaan Stabilisasi Kapur

Sebelum melakukan stabilisasi, perlu diketahui tentang kedalaman zona aktif tanah tersebut. Zona aktif adalah daerah dimana siklus dry wetting mempengaruhi perubahan kadar air yang terjadi di dalamnya. Pada umumnya, zona aktif yang terdapat dalam tanah berkisar antara $1-1,5 \mathrm{~m}$. Pada perencanaan ini akan dilakukan stabilisasi pada zona aktif dengan kedalaman $1,5 \mathrm{~m}$.

Besarnya kapur yang digunakan untuk stabilisasi berdasarkan Ingles \& Metcalf (1972) berkisar antara 38\%. Berdasarkan Sutikno dan Budi Damianto (2009), kadar kapur padam yang optimum berada pada besaran $6 \%$. Oleh karena itu pada perencanaan ini akan digunakan kadar kapur sebesar 6\% dari berat volume kering tanah.

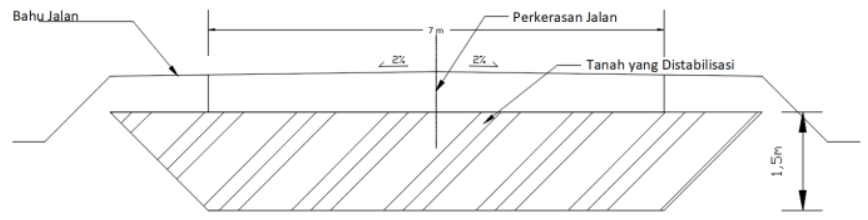

Gambar 4 Perencanaan Stabilisasi Kapur

Tabel 4 Estimasi Biaya Stabilisasi Kapur

\begin{tabular}{|c|c|c|c|c|c|c|}
\hline \multirow{2}{*}{\begin{tabular}{c|c} 
No \\
1 \\
\end{tabular}} & \multirow{2}{*}{\begin{tabular}{|l} 
Uraian Pekerjaan \\
Material
\end{tabular}} & \multirow{2}{*}{ Satuan } & \multirow{2}{*}{ Kuantitas } & & Jumlah Harga \\
\hline & & & & \multicolumn{2}{|c|}{ Harga Satuan } & \\
\hline 1 & Kapur & $\mathrm{kg}$ & 687960 & $\mathrm{Rp}$ & 950.00 & $\operatorname{Rp} 653,562,000.00$ \\
\hline II & Sewa Peralatan & & & & & \\
\hline 1 & Pemadatan Tanah & $\mathrm{m}^{3}$ & 9 & $\mathrm{Rp}$ & $65,650.00$ & $590,850.00$ \\
\hline 2 & Biaya Menghampar dengan Finisher & jam & & $\operatorname{Rp} 1,2$ & $207,314.00$ & Rp $\quad 1,207,314.00$ \\
\hline 3 & Road Mixing Plant & ton & 687.96 & $\mathrm{Rp}$ & $105,630.00$ & Rp $72,669,214.80$ \\
\hline & Total $\mathrm{H}$ & & & & & Rp $728,029,378.80$ \\
\hline
\end{tabular}

b. Penggunaan Geomembran Pada Parit untuk Jalan

Berdasarkan pengamatan secara langsung, parit yang telah ada di daerah Citraland dapat secara baik mengalirkan air dari daerah bukit ke daerah lembah (tidak terjadi genangan air), sehingga pada perencanaan ini tidak melakukan perencanaan ulang untuk parit tapi menggunakan spesifikasi parit yang telah ada. Parit yang digunakan ini kemudian akan ditutup dengan Geomembran di bagian dasarnya. Geomembran ini bertujuan untuk melindungi tanah dari perubahan kadar air yang terjadi akibat air dari parit merembes masuk ke dalam tanah.

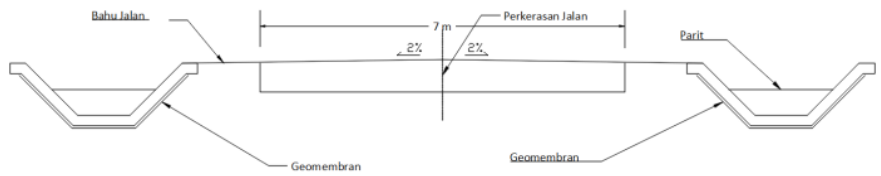

Gambar 5. Penggunaan Geomembran Pada Parit untuk Jalan

Tabel 5 .

Estimasi Biaya Penggunaan Geomembran pada Parit untuk Jalan

\begin{tabular}{|c|l|r|r|r|c|}
\hline No & \multicolumn{1}{|c|}{ Uraian Pekerjaan } & Satuan & Kuantitas & Harga Satuan & Jumlah Harga \\
\hline I & Pekerjaan Geomembran & & & & \\
\hline 1 & Pengadaan Geomembran 0,75 mm & $\mathrm{m}^{2}$ & 2400 & $\operatorname{Rp~} 35,000.00$ & $\mathrm{Rp} 84,000,000.00$ \\
\hline 2 & Pemasangan Geomembran $0,75 \mathrm{~mm}$ & $\mathrm{~m}^{2}$ & 2400 & $\mathrm{Rp} 13,000.00$ & $\mathrm{Rp} 31,200,000.00$ \\
\hline
\end{tabular}

Total Harga 
c. Perencanaan Penggantian Material Tanah Dasar untuk Rumah

Pada perencanaan ini, akan dilakukan penggantian material tanah dasar yang ekspansif dengan material tanah yang tidak ekspansif. Karena pada umumnya, perubahan kadar air terjadi di tanah bagian permukaan, sekitar 1-1,5 m dari permukaan tanah maka yang dilakukan penggantian material adalah hanya sampai kedalaman $1,5 \mathrm{~m}$ tersebut.

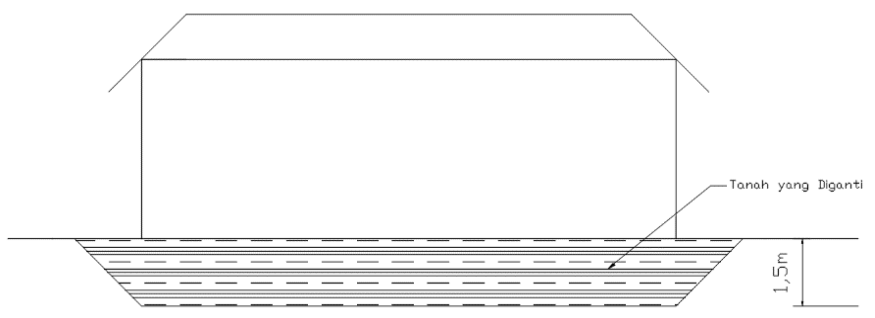

Gambar 6 Perencanaan Penggantian Tanah Dasar

Tabel 6 Estimasi Biaya Perencanaan Penggantian Tanah Dasar

\begin{tabular}{|c|c|r|r|r|r|}
\hline No & Uraian Pekerjaan & Satuan & Kuantitas & Harga Satuan & Jumlah Harga \\
\hline 1 & Pekerjaan Tanah & $\mathrm{m}^{2}$ & 300 & $\mathrm{Rp} 90,325.00$ & $\mathrm{Rp} 27,097,500.00$ \\
\hline 1 & Penggalian Tanah & 300 & $\mathrm{Rp} 203,330.00$ & $\mathrm{Rp} 60,999,000.00$ \\
\hline 2 & Pengurugan Tanah dengan Pemadatan & $\mathrm{m}^{2}$ & $\mathrm{Rp}$ & $88,096,500.00$ \\
\hline \multicolumn{5}{|c|}{ Total Harga } \\
\hline
\end{tabular}

d. Penggunaan Geomembran di Sekeliling Rumah

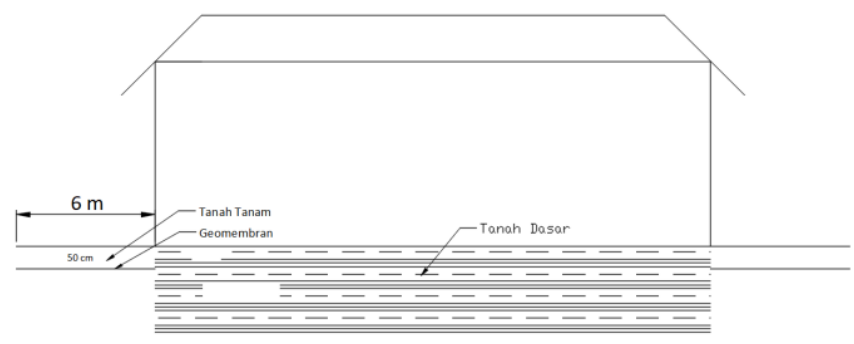

Gambar 7. Perencanaan Penggunaan Geomembran di Sekeliling Rumah

Tabel 7.

Estimasi Biaya Perencanaan Penggunaan Geomembran di Sekeliling Rumah

\begin{tabular}{|c|c|c|c|c|c|c|}
\hline \multicolumn{7}{|c|}{ Penggunaan Geomembran di Sekeliling Rumah (Pasir) } \\
\hline No & Uraian Pekerjaan & Satuan & Kuantitas & & arga Satuan & Jumlah Harga \\
\hline 1 & \multicolumn{6}{|l|}{ Pekerjaan Tanah } \\
\hline 1 & Penggalian Tanah & $\mathrm{m}^{3}$ & 60 & & $90,325.00$ & $5,419,500.00$ \\
\hline 2 & Tanah Urug Katel & $\mathrm{m}^{3}$ & 60 & $\mathrm{Rp}$ & $188,825.00$ & Rp $11,329,500.00$ \\
\hline II & \multicolumn{6}{|l|}{ Pekerjaan Geomembran } \\
\hline 1 & Pengadaan Geomembran 0,75 mm & $\mathrm{m}^{2}$ & 120 & $\mathrm{Rp}$ & $35,000.00$ & $4,200,000.00$ \\
\hline 2 & Pemasangan Geomembran 0,75 mm & $\mathrm{m}^{2}$ & 120 & $\mathrm{Rp}$ & $13,000.00$ & $\mathrm{Rp} \quad 1,560,000.00$ \\
\hline \multicolumn{6}{|c|}{$\begin{array}{ll}\text { Total Harga } \\
\end{array}$} & Rp $22,509,000.00$ \\
\hline
\end{tabular}

\section{Usulan Penyelesaian di Lembah}

Lembah pada Studi ini dimaksudkan dengan daerah yang memiliki elevasi lebih rendah daripada daerah di sekitarnya dan sangat mungkin untuk terjadi genangan air. Hal ini dikarenakan daerah lembah menerima air hujan yang jatuh dari atas serta air yang mengalir dari daerah bukit. Kondisi ini menyebabkan pembasahan akibat air hujan berdampak hingga beberapa meter di bawah permukaan tanah. Hal ini akan menyebabkan kerusakan struktural yang cukup parah apabila tanah mengalami pengeringan akibat perubahan cuaca. Oleh karena itu pada perencanaan di lembah, tanah akan diusahakan tetap dalam kondisi jenuh, atau yang juga disebut dengan metode Keep It Wet. Perencanaan menggunakan metode ini dilakukan pada saat akhir musim penghujan, dimana kondisi kadar air tanah berada dalam kondisi jenuh. Beberapa alternatif yang dapat digunakan dengan metode ini adalah sebagai berikut:

1.Penggunaan Timbunan di Bawah Konstruksi

2.Penggantian Tanah Dasar

3. Penggunaan Geomembran

4. Stabilisasi Kapur untuk Jalan

Pada Studi ini, untuk konstruksi jalan akan direncanakan dan dibandingkan antara Penggunaan Geomembran di Bawah Jalan serta Stabilisasi Kapur. Sedangkan untuk konstruksi rumah akan direncanakan dan dibandingkan antara Penggunaan Timbunan di Bawah Rumah dan Penggunaan Geomembran di sekeliling rumah.

a. Perencanaan Stabilisasi Kapur

Perencanaan Stabilisasi Kapur di Lembah sama dengan perencanaan di Bukit.

b. Penggunaan Geomembrane di Bawah Konstruksi Jalan

Pada daerah lembah, akan lebih mudah tergenang air dikarenakan akibat air hujan yang turun dari bukit, selain itu juga diakibatkan naiknya muka air tanah. Karena kondisi yang demikian maka perencanaan geomembrane ini akan berbeda dengan perencanaan Geomembran di daerah bukit. Pada perencanaan geomembran ini, posisi geomembran akan diletakkan di bawah perkerasan jalan seperti pada Gambar 8 dengan tujuan untuk mengantisipasi apabila terjadi retak pada perkerasan di jalan yang dapat menyebabkan air merembes masuk ke dalam tanah. Selain di bawah perkerasan jalan, geomembrane akan dipanjangkan secara horizontal sejauh $4 \mathrm{~m}$ dari bahu jalan. Hal ini bertujuan agar, pada saat terjadi siklus pengeringan dan pembasahan, yang mengalaminya hanya tanah yang berada di tepi geomembran. Pengerjaan dilakukan di akhir musim penghujan di saat tanah berada dalam kondisi jenuh.

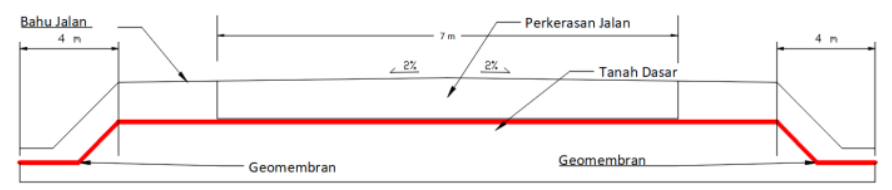

Gambar 8. Penggunaan Geomembran di Bawah Konstruksi Jalan

Tabel 8.

Estimasi Biaya Penggunaan Geomembran di Bawah Konstruksi Jalan

\begin{tabular}{|c|l|r|r|r|r|}
\hline No & \multicolumn{1}{|c|}{ Uraian Pekerjaan } & Satuan & Kuantitas & Harga Satuan & Jumlah Harga \\
\hline 1 & Pekerjaan Geomembran & & & & \\
\hline 1 & Pengadaan Geomembran $0,75 \mathrm{~mm}$ & $\mathrm{~m}^{2}$ & 6000 & $\mathrm{Rp} 35,000.00$ & $\mathrm{Rp} 210,000,000.00$ \\
\hline 2 & Pemasangan Geomembran $0,75 \mathrm{~mm}$ & $\mathrm{~m}^{2}$ & 6000 & $\mathrm{Rp} 13,000.00$ & $\mathrm{Rp} 78,000,000.00$ \\
\hline
\end{tabular}

Total Harga

Rp $288,000,000$.

c. Perencanaan Penggunaan Timbunan di Bawah Rumah

Pada perencanaan ini akan di rencanakan timbunan di bawah rumah dengan tujuan sebagai counterweight gaya angkat tanah ekspansif, maupun sebagai penutup tanah 
dasar agar tidak mengalami perubahan kadar air akibat siklus dry wetting.

Untuk menghindari terjadinya swelling pressure akibat perubahan kadar air, maka pelaksanaan perencanaan ini akan dilakukan di akhir masa penghujan dimana kondisi tanah berada di dalam kondisi jenuh sehingga swelling pressurenya sangatlah kecil. Gambar pemasangan dapat dilihat pada Gambar 9.

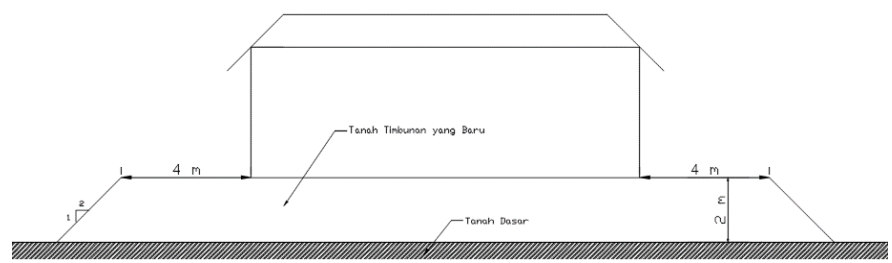

Gambar 9 Penggunaan Timbunan di Bawah Rumah

Tabel 9.

Estimasi Biaya Penggunaan Timbunan di Bawah Rumah

\begin{tabular}{|r|l|c|r|r|c|}
\hline \multicolumn{5}{|c|}{ Penggunaan Timbunan di Bawah Rumah } \\
\hline No & \multicolumn{1}{|c|}{ Uraian Pekerjaan } & Satuan & Kuantitas & Harga Satuan & Jumlah Harga \\
\hline I & Pekerjaan Tanah & 640 & Rp 203,330.00 & Rp 130,131,200.00 \\
\hline 1 & Pengurugan Tanah dengan Pemadatan & $\mathrm{m}^{2}$ & & $\operatorname{Rp} 130,131,200.00$ \\
\hline \multicolumn{6}{|c|}{ Total Harga } \\
\hline
\end{tabular}

d. Penggunaan Geomembran di Sekeliling Rumah

Perencanaan Penggunaan Geomembran di Sekeliling Rumah sama dengan perencanaan di Bukit.

\section{KESIMPULAN DAN SARAN}

\section{A. Kesimpulan}

Dalam perencanaan Studi ini didapatkan beberapa kesimpulan, yaitu:

1. Tanah pada wilayah studi berdasarkan sistem klasifikasi USCS termasuk dalam klasifikasi CH sedangkan berdasarkan sistem klasifikasi AASHTO masuk dalam klasifikasi A-7-5.

2. Berdasarkan perhitungan aktivitas tanah menggunakan Metode Skempton, ditemukan bahwa aktivitas tanah sebesar 0,43 sehingga tanah yang berada di wilayah studi masuk dalam kategori tanah yang memiliki potensi pengembangan yang tinggi.

3. Sistem perencanaan perlindungan talud dilakukan terhadap talud yang memiliki $\mathrm{SF}<1,5$ dan berada di dekat daerah konstruksi.

4. Semua perencanaan rekayasa tanah ekspansif untuk Bukit akan dilakukan dengan Metode Keep it Dry (dilakukan pada musim kemarau) sedangkan untuk Lembah akan dilakukan dengan Metode Keep it Wet (dilakukan pada akhir musim penghujan).

5. Untuk Perencanaan Rekayasa Tanah untuk Jalan di Bukit didapatkan bahwa Alternatif yang paling efisien berdasarkan harga adalah Penggunaan Geomembran pada Parit
6. Untuk Perencanaan Rekayasa Tanah untuk Jalan di Lembah didapatkan bahwa Alternatif yang paling efisien berdasarkan harga adalah Penggunaan Geomembran di Bawah Konstruksi Jalan

7. Untuk Perencanaan Rekayasa Tanah untuk Rumah di Bukit didapatkan bahwa Alternatif yang paling efisien berdasarkan harga adalah Penggunaan Geomembran di Sekeliling Rumah

8. Untuk Perencanaan Rekayasa Tanah untuk Rumah di Lembah didapatkan bahwa Alternatif yang paling efisien berdasarkan harga adalah Penggunaan Geomembran di Sekeliling Rumah

\section{B. Saran}

Dalam perencanaan Studi ini ada beberapa saran yang penulis ingin sampaikan, yaitu:

1.Perlu untuk melakukan penelitian lagi tentang kadar sulfat dalam tanah, karena apabila mencapai kadar tertentu maka penggunaan stabilis asi kapur tidaklah lagi efektif.

2. Perlu untuk dilakukan evaluasi terhadap sistem drainase yang sudah ada pada perumahan di Citraland, apakah masih menampung air pada saat musim penghujan, karena perencanaan geomembrane pada parit direncanakan dengan asumsi parit sudah dapat berfungsi dengan baik.

3. Perlu untuk melakukan penghitungan ulang terhadap harga yang digunakan, dikarenakan penulis mendapatkan harga berasal dari HSPK 2017, PT. Teknindo Geosistem Unggul, serta PT. Yoeowono Jaya Mandiri. Perusahaan lain akan memberikan harga yang berbeda dengan yang penulis gunakan.

\section{DAFTAR PUSTAKA}

[1] Bowles, J., 1984. Physical and Geotechnical Properties of Soils. 2nd ed. New York: McGraw-Hill, Inc.

[2] Bowles, J., 1984. Physical and Geotechnical Properties of Soils. 2nd ed. New York: McGraw-Hill, Inc.

[3] Chen, F., 1975. Foundation on Expansie Soils. New York: Elseveier Scientific Publication Company.

[4] Chen, F., 1975. Foundation on Expansive Soils. New York: Elseveier Scientific Publication Company.

[5] Hardiyatmo, H., 2006. Mekanika Tanah I. 4th penyunt. Yogyakarta: Gadjah Mada University Press.

[6] Ingles, O. G. \& Metcalf, J. B., 1972. Soil Stabilization Principles and Practice. Sydney: Butterworths.

[7] Mochtar, I. B., 2000. Teknologi Perbaikan Tanah dan Alternatif Perencanaan pada Tanah Bermasalah. Surabaya: Jurusan Teknik Sipil FT SP ITS.

[8] Mochtar, I. B., 2002. Rekayasa Penanggulangan Masalah Pembangunan pada Tanah-tanah Sulit. Surabaya: Jurusan Teknik Sipil FT SP ITS.

[9] Nelson, J. \& Miller, D., 1992. Expansive Soils; Problem and practice in Foundation and Pavement Engineering. New Delhi: John Wiley and Sons.

[10] Sudjianto, A. T., 2015. Tanah Ekspansif; Karakteristik dan Pengukuran Perubahan Volume. Yogyakarta: Graha Ilmu. 